\title{
Advances in the biology of JC virus and induction of progressive multifocal leukoencephalopathy
}

\author{
Pankaj Seth, Frank Diaz, and Eugene O Major \\ Laboratory of Molecular Medicine and Neuroscience, National Institute of Neurological Disorders and Stroke, National \\ Institutes of Health, Bethesda, Maryland, USA
}

\begin{abstract}
Since the initial description of progressive multifocal leukoencephalopathy (PML) in 1958, clinical and basic science investigators have demonstrated a growing interest in the area of neurovirology, with a recent focus on polyomaviruses. In this review, the authors present an overview of the biological properties of the human polyomavirus, JC virus (JCV), and its association with PML as the etiologic agent. Additionally, the authors provide a discussion of the current understanding of JCV molecular pathogenesis and therapeutic strategies. Journal of NeuroVirology (2003) 9, 236-246.
\end{abstract}

Keywords: demyelination; human polyomavirus; JC infection; PML therapy; viral pathogenesis

\section{Biology of JC virus}

JC virus (JCV) is a double-stranded circular DNA virus belonging to the family Polyomaviridae. Like the related human polyomavirus BKV, JC virus was named after the initials of the patient from whom it was first recovered. JCV virion particles are approximately $45 \mathrm{~nm}$ in diameter and display icosahedral symmetry. The prototype JCV genome Mad-1 exists as supercoiled DNA 5130 base pairs in length (Frisque et al, 1984). Initially this genome was reported to encode for two nonstructural proteins (large T, small t), three capsid proteins (VP1, VP2, and VP3), and a regulatory protein (agnoprotein) (Okada et al, 2001). Counterclockwise transcription from one of the DNA strands initiated near the origin of replication leads to the expression of the "early" large $\mathrm{T}$ and small t proteins. In contrast, "late" transcripts made from the opposite strand of DNA in a clockwise direction encode for the agnoprotein, as well as the virion structural proteins, VP1, VP2, and VP3 (Frisque et al, 1984). The presence

Address correspondence to Eugene O. Major, PhD, Chief, Laboratory of Molecular Medicine and Neuroscience, NINDS, NIH, Building 36, Room 5W21, 36 Convent Drive, Bethesda, Maryland 20892-4164, USA. E-mail: majorg@ninds.nih.gov

The authors wish to thank Peter Jensen, Jean Hou, and Blanche Curfman for critical review and editing of the manuscript. They gratefully acknowledge Peter Jensen for his help with preparing the figure. Frank Diaz is in part supported by the office of Loan Repayment and Scholarship at NIH.

Received 28 October 2002; revised 21 November 2002; accepted 5 December 2002. of three additional early proteins, $\mathrm{T}^{\prime} 135, \mathrm{~T}^{\prime} 136$ and $\mathrm{T}^{\prime} 165$, has more recently been documented in lytically infected cells (Trowbridge and Frisque, 1995). These $\mathrm{T}^{\prime}$ proteins are reported to be involved in JCV DNA replication and interactions with several cellular proteins that may play roles in interference with certain T-antigen functions (Frisque, 2001). The large T protein also interacts with p53 (Staib et al, 1996), a tumor suppressor protein, that influences cell cycle and apoptosis. Studies have shown p53 accumulation and polymorphisms in patients with progressive multifocal leukoencephalopathy (PML) (Power et al, 2000; Ariza et al, 1996). Even though apoptosis is a factor in many neurodegenerative disorders, its impact on PML remains elusive. To our knowledge, with the exception of the multinuclear astrocytes commonly observed in PML brain tissue, only two studies suggest that apoptosis may contribute to the PML demyelinating process (Yang and Prayson, 2000; Richardson-Burns et al, 2002). This laboratory is currently investigating whether apoptotic pathways are associated with JCV pathogenesis and if such pathways contribute to the central nervous system (CNS) demyelination in PML. The role of the small t protein remains unclear and has not been conclusively linked with viral replication or pathogenesis in humans. However, there is evidence for small $t$ involvement in the transformation of infected rodent and nonhuman primate cells (London et al, 1978; Walker et al, 1973). The virion particle comprises all three viral capsid proteins, although VP1, the largest capsid protein, is capable of self-assembling into icosahedral 
particles, independent of VP2 and VP3 (Chang et al, 1997). VP1 also contains the epitopes for antibody induction and recognition. VP1 has been successfully expressed using recombinant baculoviruses and the resulting recombinant VP1 has been demonstrated to form virus-like particles (VLPs) with a typical morphology of empty JCV capsids. VP1 VLPs have been described as an efficient transporter system with potential for gene therapy and PML-specific vaccine development (Goldmann et al, 1999, 2000). Agnoprotein, a 71-amino acid polypeptide, is encoded by sequence at the $5^{\prime}$ end of the JCV late gene region. The presence of agnoprotein results in suppression of cell growth and cell proliferation by deregulating cell cycle progression and stalling cells in G2/M phase (Darbinyan et al, 2002). Further, it has been shown that agnoprotein-mediated suppression of cell proliferation is independent of $\mathrm{T}$ antigen, probably via enhancement of tumor suppressor protein p21 expression and interaction with p53 (Darbinyan et al, 2002). The agnoprotein is shown to interact with $\mathrm{T}$ protein to down-regulate T protein-modulated viral DNA replication, as well as play a role in capsid assembly (Safak et al, 2001; Major, 2001). Furthermore, a newly synthesized polyclonal agnoprotein antibody has been used to demonstrate that agnoprotein is expressed in, and mainly confined to, the cytoplasm of JCVinfected cells, both in culture and brains of PML patients (Okada et al, 2002).

Recent studies have shown that treatment of cells with neuraminidase, protease, or phospholipase blocks JCV binding. However, viral infection was specifically abrogated only by neuraminidase, suggesting that receptors for JCV may contain sialic acid. Studies have since confirmed that JCV uses widely expressed alpha 2,6-linked sialic acid residues on glycoproteins for attachment to the cell membrane of several cell types (Liu et al, 1998). Virions are transported to the nucleus through a clathrin-dependent endocytosis (Pho et al, 2000) where viral replication and assembly occurs. Furthermore, most recent evidence suggests that the oligosaccharides of glycoproteins and glycolipids work as JCV receptor based on the fact that neoglycoproteins and gangliosides with biologically relevant binding to JCV inhibited JCV infection in human glial SVG-A and human neuroblastoma IMR-32 cells (Komagome et al, 2002).

The role of DNA binding proteins in cell typespecific regulation of JCV DNA replication and transcription has been emphasized recently (Raj and Khalili, 1995). A number of such proteins has been studied in relation to JCV infection, including Sp1 (Henson et al, 1992), c-Jun (Amemiya et al, 1992), nuclear factor kappa B (NF- $\mu \mathrm{B})$ (Ranganathan and Khalili, 1993), Tst-1 (Wegner et al, 1993), YB-1 (Kerr et al, 1994), GBP-i (Raj and Khalili, 1994), Pur-alpha (Chen and Khalili, 1995), and NF-1 (Amemiya et al, 1989). NF-1 encompasses a family of multifunctional proteins that participate in transcription and replication of several genes in an organ- and cell type- specific manner. The NF-1 family of transcription factors is divided into four subclasses, A, B, C, and D or $\mathrm{X}$. NF-1 has several binding sites in the regulatory region of JCV and has been implicated in supporting JCV infection (Raj and Khalili, 1995). The NF-1X class member in particular has stirred significant interest among investigators because it is expressed at higher levels than the other classes in cells that are susceptible to JCV infection (Sumner et al, 1996). Human fetal glial cells and the hematopoietic progenitor cell line KG-1 are two recently cited examples with correlation of JCV permissiveness and NF-1X expression. The role of NF-1 in JCV activity has been confirmed by several studies demonstrating that KG-1 cells, which lose JCV susceptibility upon differentiation to macrophage-like cells, exhibit a concomitant down-regulated NF-1X expression. However, transfection with NF-1 class X expression vectors, and subsequent overexpression of NF-1X protein in the same differentiated cells, restored susceptibility to JCV infection (Monaco et al, 2001).

The nucleotide sequence arrangement of the JCV regulatory region is believed to be a predominant factor affecting viral host range and cellular tropism. In fact, a classification scheme has been recently proposed to distinguish between JCV variants based on sequence differences in their regulatory regions (Jensen and Major, 2001). Mad-1 sequence includes a 98-bp tandem repeat in the regulatory region. Such arrangements are most frequently identified in brain biopsies from PML patients. In contrast, viral isolates from urine samples generally exhibit regulatory region sequence rearrangements referred to as "archetype," having only a single copy of the 98-bp Mad-1 regulatory region sequence structure with insertions of 23- and 66-bp sequences. The archetype strain has been shown to be biologically inactive in vitro, whereas in contrast the Mad-1 and other similarly arranged strains have the most robust viral activity.

\section{Incidence and detection of JCV}

JCV has a worldwide distribution, with asymptomatic JCV infection seen in more than $80 \%$ of adults, as defined by the presence of JCV antibodies (Major et al, 1992; Weber et al, 1997a). Serological studies indicate that primary infection occurs in childhood. JCV strains worldwide have been classified into more than 10 main genotypes based on the phylogenetic analyses of viral VP1 gene (Agostini et al, 2001). A correlation between JCV genotypes and human populations appears to be evident based on the geographical distribution of JCV. Within populations, a parent-to-child mode of viral transmission has been demonstrated (Kunitake et al, 1995; Suzuki et al, 2002). JCV was initially designated as strictly neurotropic, and was assumed to replicate and multiply only in human glial cells. However, as recent 
advances suggest, JCV is not restricted to the CNS, and can infect diverse cell types within human hosts (Major, 2001). The demonstration of active JCV replication in non-CNS tissues as indicated by polymerase chain reaction (PCR), in situ hybridization, Southern blot, and/or restriction enzyme digest patterning has advanced our understanding of JCV pathogenesis and its association with PML. Furthermore, the development of monoclonal and polyclonal antibodies to viral $\mathrm{T}$ protein and capsid proteins has helped in following the course of infection in vitro and in vivo by allowing detection of JCV-infected cells and tissues. Detection of JCV agnoprotein by use of a new specific polyclonal antibody (Ab) has been suggested as an appropriate marker for PML diagnosis and a progressive JCV infection (Okada et al, 2002). The presence of host antibodies against JCV has traditionally been determined by hemagglutination inhibition of human type $\mathrm{O}$ erythrocytes; however, the recent development of a JCV-specific enzyme-linked immunosorbant assay (ELISA) has facilitated the screening of human serum samples and subsequently larger seroepidemiological studies of JCV infection (Hamilton et al, 2000). Collectively, all these methods of detection have been used as markers for PML. The confirmatory diagnosis remains the detection of JCV DNA in demyelinated lesions of brain biopsy tissue or cerebrospinal fluid (CSF) by in situ DNA hybridization or PCR amplification, respectively.

\section{Viral pathogenesis and clinical implications of JCV infection}

Within the CNS, JCV productively infects oligodendrocytes. Demyelination resulting from this lytic infection and destruction of oligodendrocytes is the pathological cause of the neurological impairments seen in PML. PML was first described as a neuropathologic entity in 1958 (Astrom et al, 1958), which was later linked to a viral etiology in 1971, when a unique human polyomavirus was isolated from primary human fetal glial cell cultures inoculated with brain extracts from PML patients (Padgett et al, 1971). PML is a chronic, progressive, usually fatal disease in humans, characterized by neuropathological features such as multifocal demyelination, enlarged oligodendrocytes with nuclear inclusions, bizarre looking astrocytes having lobutaled hyperchromatic nuclei, as well as astrocytes containing mitotic bodies (Frisque and White, 1992; ZuRhein, 1969; ZuRhein and Chou, 1965). Pathological alterations of PML are seen in the cerebrum, cerebellum, or brain stem (Richardson, 1961; ZuRhein, 1969; Richardson and Webester, 1983). Although cerebral cortex and deep gray matter appear normal, myelin loss is evident in areas of retraction within subcortical or deep white matter. Histopathologically, demyelinated PML lesions exhibit significant oligodendrocyte death. Remaining intact oligodendrocytes are usually enlarged with nuclear inclusions (Richardson, 1961; ZuRhein GM, 1969). JCV DNA, as well as early and late viral proteins, have been reported in nuclei of infected oligodendrocytes (Greenlee and Keeney, 1986; Aksamit et al, 1987). Electron microscopy of PML brain tissue reveals crystalline arrays of viral particles within infected oligodendrocytes. PML can be considered an opportunistic infection that is almost always observed in immunosuppressed patients in clinical settings such as acquired immunodeficiency syndrome (AIDS), certain cases of advanced malignancy, and organ transplantation. Two to five percent of patients with AIDS develop PML, usually leading to rapid mortality due to lack of cellular immunity (Berger and Concha, 1995; Cinque et al, 1997). The higher incidence of PML in AIDS patients as compared to other immunocompromised disorders, suggest that the presence of HIV-1 in the CNS may play a direct, or indirect, role in JCV pathogenesis. The fact that the human immunodeficiency virus type 1 (HIV-1)-encoded transregulatory protein, Tat, significantly promotes the rate of transcription from the JCV late promoter supports the hypothesis of this relationship between PML and HIV-1 infection (Chowdhury et al, 1993). In immunocompromised individuals, PML involves both a humoral and a T cell-mediated immune response. The impact of the cellular immune response against JCV on the clinical outcome of HIV-positive as well as HIV-negative individuals with PML has been recently examined. These studies show a better clinical outcome for the patients with JCV-specific cellular immune response (Koralnik et al, 2001, 2002). In PML cases without AIDS, general impairment of cell-mediated immune response, along with severe and selective impairment of cell-mediated immune response to JCV, has also been shown (Willoughby et al, 1980).

Before AIDS appeared as a global health threat, PML occurred as an extremely rare complication of malignant diseases such as lymphomas and leukemias, protracted granulomatous disorders such as tuberculosis, sarcoidosis, and immunosuppression for collagen vascular disease or organ transplantation (Greenlee, 1989). However, with the advent of AIDS as a pandemic, the number of PML cases reported worldwide has increased dramatically, and as AIDS patients are now living longer with improved AIDS therapies, the incidence of PML and its complexity in such patients may be expected to rise. JCVinduced PML has hence achieved greater clinical interest. At present, it is unclear whether development of PML is subsequent to the initial entry of JCV into the CNS with infected lymphocytes, or whether it follows reactivation of a persistent latent infection. The underlying mechanism(s) by which PML occurs is an important focus of current research efforts.

For decades, definitive diagnosis of PML required brain biopsy, and detection of JCV DNA or viral antigens by in situ nucleic acid hybridization or 
immunohistochemistry, respectively. Gene amplification techniques have been successfully applied for the detection of JC viral genome sequences in various tissue types, with remarkable results. For instance, the presence of JC viral DNA has been reported in urine from normal individuals, as well as from PML patients. Extensive PCR studies on peripheral blood mononucleocytes have demonstrated the presence of JCV DNA in more than $75 \%$ of PML patients, in a large number of HIV-1-seropositive patients, individuals with renal transplants, and cancer patients (Dorries et al, 1994; Tornatore et al, 1992). Seroepidemiologic evidence for worldwide distribution of JCV has been confirmed by molecular techniques demonstrating the presence of JCV DNA in the peripheral blood of a majority of healthy individuals. PCR analysis of CSF has shown high sensitivity for viral detection in $80 \%$ to $92 \%$ of biopsy-confirmed PML patients, some even with very low viral copy numbers (McGuire et al, 1995; Weber et al, 1994). The diagnostic value of the detection of JCV DNA in CSF and the correlation between the JCV burden in patient CSF samples and PML prognosis has been proposed (Garcia De Viedma et al, 2002).

\section{Mechanisms of JCV pathogenesis}

In addition to PML, JCV has been implicated in several cancers, including tumors of neural origin (Caldarelli-Stefano et al, 2000; Del Valle et al, 2001; Khalili et al, 1999). Hence, the focus on understanding pathways that lead to viral pathogenesis is important. Recent advances in polyomavirus research have emphasized the involvement of receptors, DNAbinding proteins, as well as variation in the viral regulatory region.

\section{Initial infection}

Based on seroepidemiological evidence, introduction of JCV into humans appears to follow a common route of infection. Initially, respiratory inhalation was considered the primary and most likely route of infection, but reports of detection of JCV in lung tissue is uncommon. However, the discovery of the presence of JCV DNA in human tonsillar stromal cells and tonsillar lymphocytes in 1998 has reopened the hypothesis of respiratory tract involvement in JCV infection (Monaco et al, 1998). Based on information available from the literature and our present understanding of the virus, we have illustrated different steps and possible sites involved in JCV dissemination throughout the human host in Figure 1. Recent studies have also demonstrated the presence of JCV in epithelial cells of the human colon (Ricciardiello et al, 2000). The results provide evidence for a potential gastrointestinal intake, although the virus has previously been shown to be unstable under the conditions of oral ingestion or gastrointestinal infection. However, recent evidence suggest that the virion particle may remain viable at low $\mathrm{pH}$ (Bofill-Mas et al, 2001). Initial infection of JCV in humans remains a topic of debate; however, the worldwide distribution of this virus calls for research efforts into better understanding of the route of viral infection.

Viral latency within the host

The presence of JCV in urine samples from healthy, as well as PML patients, suggests a possible site for viral latency and subsequent reactivation under immunocompromised conditions in the kidney (Figure 1). The archetype strain of JCV is the most commonly found strain in kidneys. Interestingly, the archetype regulatory region sequence lacks biological activity in vitro and is not as prevalently found in the brain tissue of PML patients as strains containing a prototype or other prototype-like regulatory region. This suggests the possibility of rearrangements and deletions during JC viral replication in the kidney or brain (Daniel et al, 1996). Interestingly, there appears to be a correlation between the presence of archetype JCV isolates from plasma and CSF with PML survivability. Comparatively, patients having strains with tandem repeat regulatory region sequence structure are less likely to survive PML (Pfister et al, 2001). The inability of the archetype strain to replicate effectively in glial cell cultures has been attributed to the failure of the early viral promoter to produce sufficient mRNA to carry out $\mathrm{T}$ protein-mediated viral DNA replication (Daniel et al, 1996). JCV has also been reported in the bone marrow and spleen of PML patients, suggesting that lymphoid tissues may be a potential site of viral latency (Dorries et al, 1994; Houff et al, 1988; Schneider and Dorries, 1993). Further evidence comes from the demonstration of the JCV susceptibility of the CD34+ cell lines KG-1 and KG-1a primary CD34+ hematopoietic progenitor cells, primary B lymphocytes, and stromal tonsillar cells (Monaco et al, 1998).

A clear understanding of the site and mechanism of JCV reactivation remains an unanswered question, although the majority of evidence suggests immunosuppression to be a major underlying factor. Several investigators believe that reactivation of JCV may occur following conditions arising from immune suppression that may be conducive for rearrangements and changes in the regulatory region during viral DNA replication. Others, however, believe that loss of specific immune cells that control active infection, or viral replication, results in reactivation. Immunosuppression may hence lead to synthesis or release of biologically active tandem repeat prototype-like strains of JCV from the relatively inactive archetype strain. Evidence that not all JCV-seropositive, immunocompromised individuals develop PML necessitates studies to address the issue of viral latency and reactivation, independent of immune status. The case histories of PML patients studied over the last decades show that, in some patients, PML does not always follow its typical 


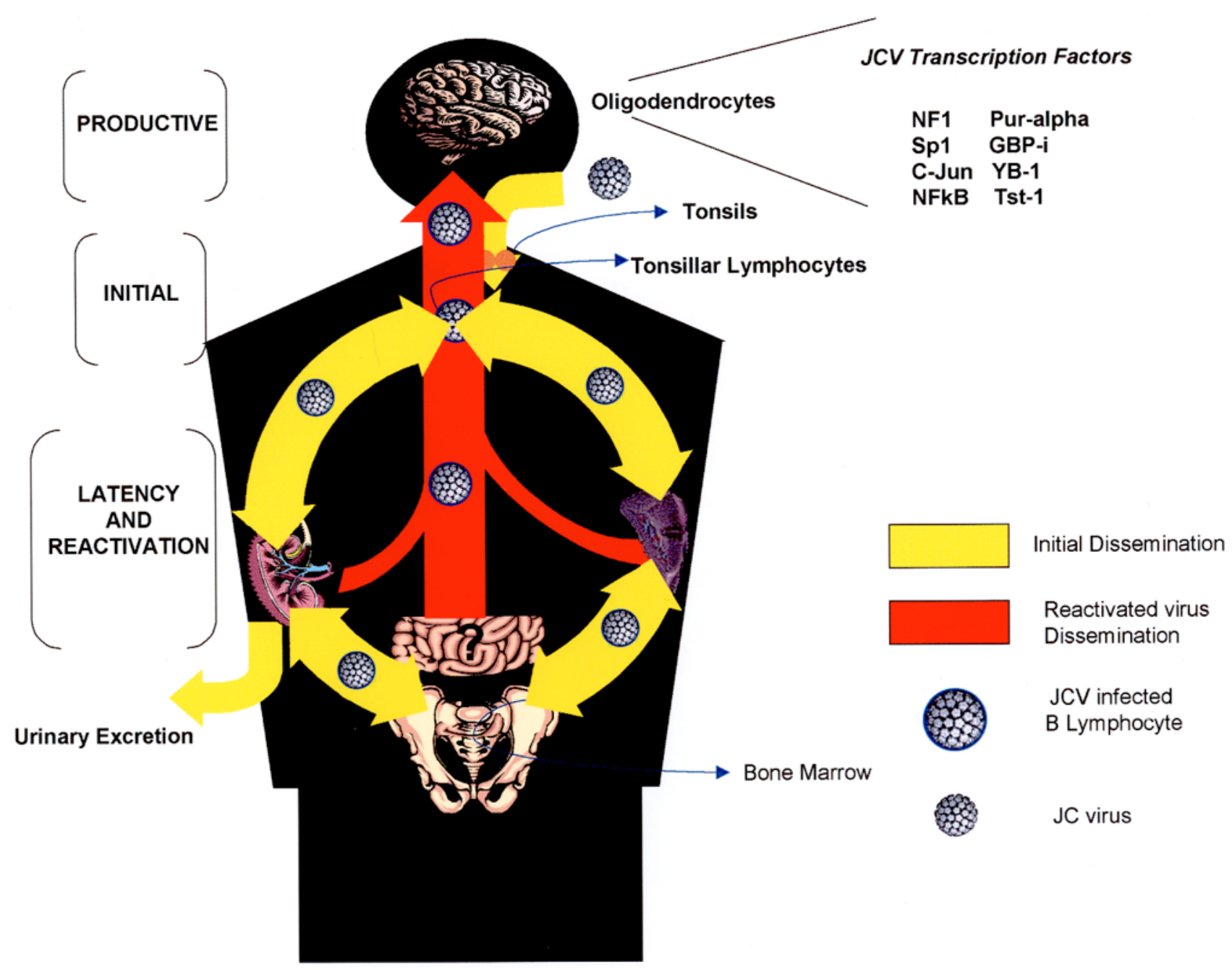

Figure 1 Initial JCV infection may occur through respiratory inhalation followed by tonsillar B lymphocyte dissemination to one or more organs and tissues, including other B lymphocytes, kidneys (one shown), spleen, and bone marrow, where JCV is believed to persist in a latent state. Data are still inconclusive whether colon epithelial cells play a role in the JCV infectious cycle. Following immunosuppression, JC virus productively replicates and could make its way into the brain via B-lymphocyte trafficking. Once in the brain, productive infection is triggered and/or maintained by a number of cellular transcription factors, leading to demyelination and PML. Mainly archetype strains have been found in the urine of healthy and infected patients. Other organs mentioned in the text are not shown for simplicity.

features of being progressive, multifocal, and restricted to white matter. Currently, clinical and basic science investigators in the field of PML are initiating a consensus for redefining the terminology and definition of PML (Cinque et al, 2003; Journal of NeuroVirology 9(s1), report of a conference).

\section{Dissemination of JCV to brain}

Absence of animal models for JCV-induced demyelination leading to PML has hampered our understanding of the trafficking of JCV to the brain and the initiation and development of CNS infection. Unsuccessful attempts to develop relevant transgenic mice, or produce acute infection in nonhuman primates, have made the mechanism(s) of JCV entry into the human brain more elusive. The presence of JCV in different organs such as kidney, brain, heart, spleen, bone marrow, lung, liver, and colon (Major et al, 1992; Weber and Major, 1997b), as well as positive in situ DNA hybridization for JCV in cells surrounding blood vessels in brain tissue, suggest a hematogenous route for progression of infection within the host (Houff et al, 1988). JCV has been shown to be present in prostate tissue as well (Zambrano et al, 2002). Efforts have been directed toward studying different lymphocyte populations and their involvement in trafficking virus to the brain. For example, the presence of JCV infected B lymphocytes in PML brain lesions (Major et al, 1990) could be partially explained by the enriched blood supply circulating these cells through the brain. JCV has been shown to bind to several different cell types, both susceptible and nonsusceptible. Virus internalization occurs quite rapidly 
via clathrin-dependent receptor-mediated endocytosis (Pho et al, 2000). However, highly susceptible cells, like glial cells, positively regulate and promote JCV transcription and DNA replication due to the presence of specific NF-1 DNA-binding proteins. $\mathrm{NF}-1$ class $\mathrm{X}$, in conjunction with other transcription factors, regulates JCV activity in glial cells, resulting in a productive infection, that spreads virus to adjacent cells. Infected oligodendrocytes undergo lytic infection, resulting in CNS demyelination. The loss of the myelin sheath surrounding neuronal axons impairs signal transmission, causing compromised neurological function and appearance of clinical symptoms consistent with affected brain regions. The condition worsens as demyelinated lesions grow. Prognosis of such PML patients is usually poor, succumbing to the disease within months of clinical diagnosis, with some exceptions (Major et al, 1992; Kepes et al, 1975).

\section{Current therapies for PML}

Because AIDS currently accounts for most of PML cases, it is not surprising that antiretroviral therapies have been extensively used to treat AIDS-associated PML. Studies have shown prolonged survival and improved or stabilized neurological conditions in AIDSassociated PML patients undergoing highly active antiretroviral therapy (HAART) (Clifford et al, 1999; De Luca et al, 2000b). Cidofovir, a nucleotide analog used to treat cytomegalovirus (CMV) retinitis, proved to have considerable in vitro activity against polyomaviruses (Andrei et al, 1997) and has therefore been administered in combination with HAART to treat PML. Although some case studies did not find improvement following cidofovir treatment (Marra et al, 2002; Houston et al, 2001), anecdotal reports and small studies have shown prolonged survival and improved radiological and neurological conditions in AIDS-associated PML (Portilla et al, 2000; De Luca et al, 1999). However, identifying cidofovir as the agent responsible for the clinical effects is difficult in most of these studies. Some studies have reported cidofovir to be effective only after nonresponsive HAART treatment (De Luca et al, 1999; Razonable et al, 2001). This temporal relation between the start of cidofovir treatment and clinical improvement fails to eliminate the long-term effects of HAART. Also, cidofovir has proven ineffective when used as the sole treatment (Houston et al, 2001). Although undetectable levels of JCV DNA after therapy is associated with longer survival (De Luca et al, 2001; Giudici et al, 2000; Miralles et al, 1998), cidofovir's ability to decrease JCV DNA in CSF more rapidly is inconclusive (Gasnault et al, 2001; De Luca et al, 2000a). Also, cidofovir did not show any effect in JCV multiplication as well as replication in vitro (Hou and Major, 1998). Despite some promising results, a recent controlled pilot study showed no benefits fol- lowing cidofovir treatment in HIV-associated PML patients, even in conjunction with potent antiretroviral therapy (Marra et al, 2002). These results suggest cidofovir, even as a HAART adjunct, is not as effective as previously thought.

Although the outcome of some clinical studies seem promising, they fall short of presenting the clinician and patient with a reliable therapy for PML. Patients with high JC viral load and/or low CD4+ cell counts do not respond to HAART treatment or HAART-cidofovir combinations (De Luca et al, 2001; Taoufik et al, 2000). Moreover, prolonged survival without neurological improvement after potent combined antiretroviral treatment including cidofovir has been reported (Gasnault et al, 1999). The current belief is that immune reconstitution is a requisite for clinical improvement. However, some patients develop PML shortly after HAART treatment. Miralles et al (2001) reported clinical and radiological deterioration following HAART, accompanied by reductions in HIV viral load and increased CD4+ cell counts in 3 out of 28 patients, as well as inflammatory changes in half of the PML patients treated with HAART. These findings raise the possibility that rapid immune reconstitution might worsen the course of PML in some patients. However, it is unclear whether initial deterioration precedes improvement as has been previously reported (Miralles et al, 1998).

Additional therapies that have been considered include topoisomerase inhibitors, alpha-interferon, or heparin sulfate. But in general, no clear benefit from these treatments has been shown (Mamidi et al, 2002). A pre-HAART open study suggested some benefit from alpha-interferon therapy (Huang et al, 1998), but a more recent study suggested no additional benefit when administered in combination with HAART (Geschwind et al, 2001). Recently, nontoxic doses of chlorpromazine, an antipsychotic, were shown to be effective at inhibiting JCV multiplication and dissemination in an in vitro model (Atwood, 2001), but further studies are warranted before it can be considered for use in PML patients. Another area of research that shows some promise is antisense oligonucleotides. These have been used to hinder viral DNA replication and transcription (Ma and Doan, 1994) and techniques for widespread and targeted delivery into the brain are being explored (Levy et al, 1997). Cytosine arabinoside or Ara-c inhibits JCV replication and multiplication in vitro (Hou and Major, 1998), but a controlled clinical study failed to show any benefits (Hall et al, 1998). As the intrathecal drug delivery was inefficient in targeting demyelinating areas, a new clinical trial is being conducted using convection enhanced delivery (Levy et al, 1997).

It is difficult to compare many of the results reported because of the different parameters used for both diagnosis and, subsequently, as measures of improvement. Cinque et al (2003) proposed a classification scheme for PML in order to develop consistency among researchers both for diagnosis and 


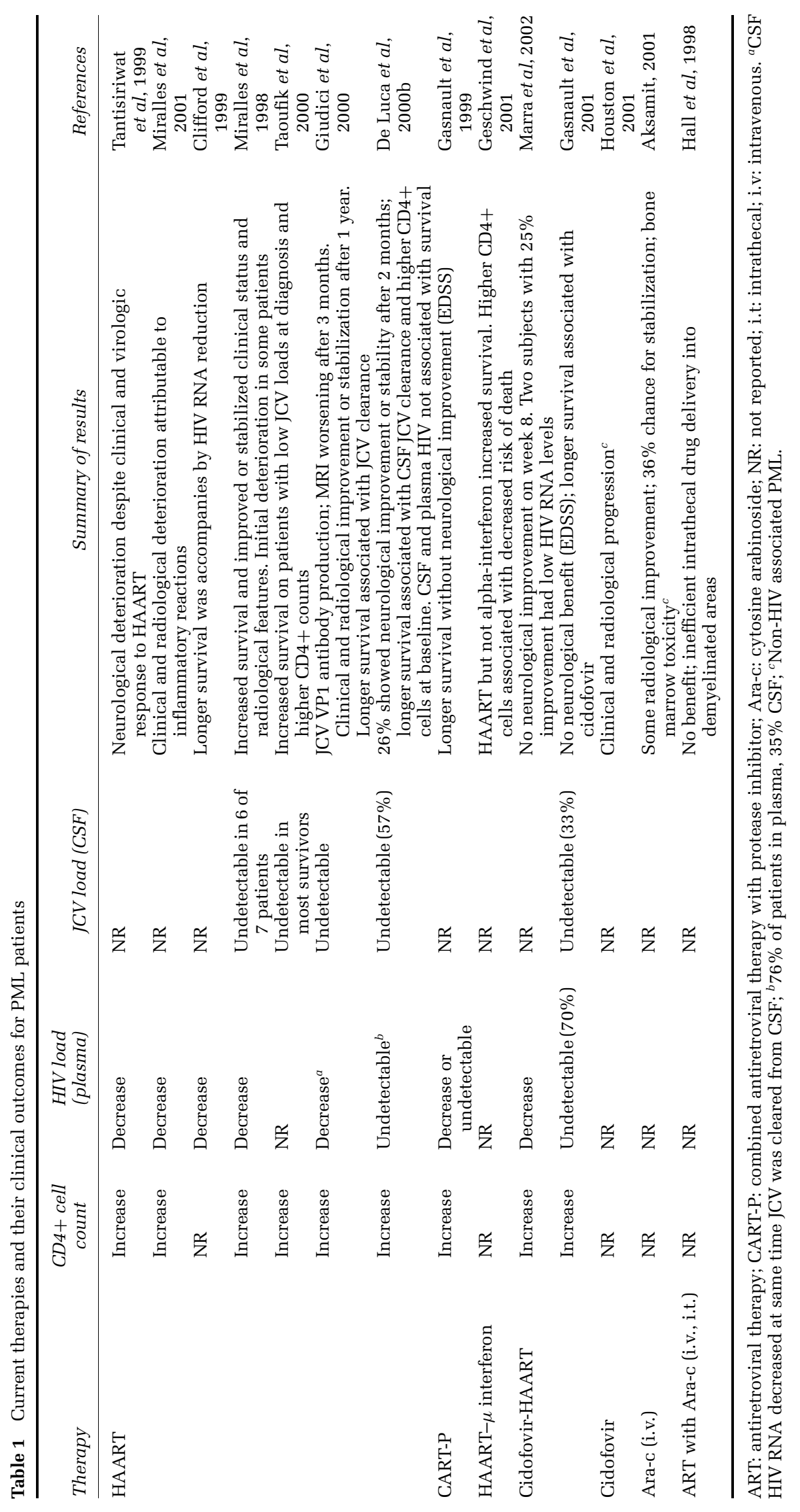


therapy outcome. Such a classification is important especially because a growing number of PML cases deviate from the more typical progressive and lethal types, common in earlier years (Cinque et al, 2003). Table 1 summarizes some of the most recent results.

Of the treatments discussed, HAART is the most used treatment for AIDS-associated PML to date. HAART is somewhat effective in $50 \%$ of patients, but low JC viral loads, early treatment administration, and high CD4+ cell counts are usually prerequisites for positive prognosis. Although some might argue that the benefits of cidofovir as an effective adjunct to HAART are inconclusive, the recent study conducted by Marra et al (2002) shows that it offers

\section{References}

Agostini HT, Jobes DV, Stoner GL (2001). Molecular evolution and epidemiology of JC virus. In: Human polyomaviruses: molecular and clinical perspectives. Khalili K, Stoner GL (eds). New York: John Wiley and Sons, pp 491-526.

Aksamit AJ (2001). Treatment of non-AIDS progressive multifocal leukoencephalopathy with cytosine arabinoside. J NeuroVirol 7: 386-390.

Aksamit AJ, Major EO, et al (1987). Diagnosis of progressive multifocal leukoencephalopathy by brain biopsy with biotin labeled DNA:DNA in situ hybridization. J Neuropathol Exp Neurol 46: 556-566.

Amemiya K, Traub R, et al (1989). Interaction of a nuclear factor-1-like protein with the regulatory region of the human polyomavirus JC virus. J Biol Chem 264: 70257032.

Amemiya K, Traub R, et al (1992). Adjacent nuclear factor-1 and activator protein binding sites in the enhancer of the neurotropic JC virus. A common characteristic of many brain-specific genes. J Biol Chem 267: 14204-14211.

Andrei G, Snoeck R, et al (1997). Activities of various compounds against murine and primate polyomaviruses. Antimicrobial Agents Chemother 41: 587-593.

Antinori A, Ammassari A, et al (2001). Epidemiology and prognosis of AIDS-associated progressive multifocal leukoencephalopathy in the HAART era. J NeuroVirol 7: 323-328.

Ariza A, von Uexkull-Guldeband C, et al (1996). Accumulation of wild-type p53 protein in progressive multifocal leukoencephalopathy: a flow of cytometry and DNA sequencing study. J Neuropathol Exp Neurol 55: 144149.

Astrom KE, Mancall EL, et al (1958). Progressive multifocal leukoencephalopathy. Brain 81: 93-127.

Atwood WJ (2001). A combination of low-dose chlorpromazine and neutralizing antibodies inhibits the spread of JC virus (JCV) in a tissue culture model: implications for prophylactic and therapeutic treatment of progressive multifocal leukencephalopathy. J NeuroVirol 7: 307-310.

Berger JR, Concha M (1995). Progressive multifocal leukoencephalopathy: the evolution of a disease once considered rare. J NeuroVirol 1: 5-18. no additional benefit, leaving the patient with only one effective treatment, HAART. The appearance of PML during HAART in some cases calls for further studies on immunoregulation during the progression and remission of PML in order to develop new treatments. The need of an effective therapy for this usually fatal disease continues and is further highlighted by the slow advances in treatment of PML when compared to other AIDS-associated disorders during the HAART era (Antinori et al, 2001). It is hoped that improved understanding of the underlying mechanisms of JC infection in humans will drive the emergence of new therapeutics and strategies for ameliorating the sequelae of neuroinfection.

Bofill-Mas S, Formiga-Cruz M, et al (2001). Potential transmission of human polyomaviruses through the gastrointestinal tract after exposure to virions or viral DNA. J Virol 75: 10290-10299.

Caldarelli-Stefano R, Boldorini R, et al (2000). JC virus in human glial-derived tumors. Hum Pathol 31: 394395.

Chang D, Fung CY, et al (1997). Self-assembly of the JC virus major capsid protein, VP1, expressed in insect cells. J Gen Virol 78 (Pt 6): 1435-1439.

Chen NN, Khalili K (1995). Transcriptional regulation of human JC polyomavirus promoters by cellular proteins YB-1 and Pur alpha in glial cells. J Virol 69: 5843-5848.

Chowdhury M, Kundu M, et al (1993). GA/GC-rich sequence confers Tat responsiveness to human neurotropic virus promoter, JCVL, in cells derived from central nervous system. Oncogene 8: 887-892.

Cinque P, Koralnik IJ, et al (2003). The evolving face of HIV-related progressive multifocal leukoencephalopathy: Defining a consensus terminology. J NeuroVirol 9(s1): (In press).

Cinque P, Scarpellini P, et al (1997). Diagnosis of central nervous system complications in HIV-infected patients: cerebrospinal fluid analysis by the polymerase chain reaction. AIDS 11: 1-17.

Clifford DB, Yiannoutsos C, et al (1999). HAART improves prognosis in HIV-associated progressive multifocal leukoencephalopathy. Neurology 52: 623-625.

Daniel AM, Swenson JJ, et al (1996). Sequences within the early and late promoters of archetype JC virus restrict viral DNA replication and infectivity. Virology 216: 90101.

Darbinyan A, Darbinian N, et al (2002). Evidence for dysregulation of cell cycle by human polyomavirus, JCV, late auxiliary protein. Oncogene 21: 5574-5581.

De Luca A, Fantoni M, et al (1999). Response to cidofovir after failure of antiretroviral therapy alone in AIDSassociated progressive multifocal leukoencephalopathy. Neurology 52: 891-892.

De Luca A, Giancola ML, et al (2001). Potent anti-retroviral therapy with or without cidofovir for AIDS-associated progressive multifocal leukoencephalopathy: extended follow-up of an observational study. J NeuroVirol 7: 364368. 
De Luca A, Giancola ML, et al (2000a). Cidofovir added to HAART improves virological and clinical outcome in AIDS-associated progressive multifocal leukoencephalopathy. AIDS 14: F117-F121.

De Luca A, Giancola ML, et al (2000b). The effect of potent antiretroviral therapy and JC virus load in cerebrospinal fluid on clinical outcome of patients with AIDS-associated progressive multifocal leukoencephalopathy. J Infect Dis 182: 1077-1083.

Del Valle L, Gordon J, et al (2001). Detection of JC virus DNA sequences and expression of the viral regulatory protein T-antigen in tumors of the central nervous system. Cancer Res 61: 4287-4293.

Dorries K, Vogel E, et al (1994). Infection of human polyomaviruses JC and BK in peripheral blood leukocytes from immunocompetent individuals. Virology 198: 59-70.

Frisque RJ (2001). Structure and function of JC virus $\mathrm{T}^{\prime}$ proteins. J NeuroVirol 7: 293-297.

Frisque RJ, Bream GL, et al (1984). Human polyomavirus JC virus genome. J Virol 51: 458-469.

Frisque RJ, White FA (1992). The molecular biology of JC virus, causative agent of progressive multifocal leukoencephalopathy. In: Molecular neurovirology, Roos R (ed.). pp. 25-158, Humana Press, New Jersey.

Garcia De Viedma D, Diaz Infantes M, et al (2002). JC virus load in progressive multifocal leukoencephalopathy: analysis of the correlation between the viral burden in cerebrospinal fluid, patient survival, and the volume of neurological lesions. Clin Infect Dis 34: 15681575.

Gasnault J, Kousignian P, et al (2001). Cidofovir in AIDSassociated progressive multifocal leukoencephalopathy: a monocenter observational study with clinical and JC virus load monitoring. J NeuroVirol 7: 375381.

Gasnault J, Taoufik Y, et al (1999). Prolonged survival without neurological improvement in patients with AIDSrelated progressive multifocal leukoencephalopathy on potent combined antiretroviral therapy. J NeuroVirol 5: 421-429.

Geschwind MD, Skolasky RI, et al (2001). The relative contributions of HAART and alpha-interferon for therapy of progressive multifocal leukoencephalopathy in AIDS. J NeuroVirol 7: 353-357.

Giudici B, Vaz B, et al (2000). Highly active antiretroviral therapy and progressive multifocal leukoencephalopathy: effects on cerebrospinal fluid markers of JC virus replication and immune response. Clin Infect Dis 30: 95-99.

Goldmann C, Petry H, et al (1999). Molecular cloning and expression of major structural protein VP1 of the human polyomavirus JC virus: formation of virus-like particles useful for immunological and therapeutic studies. J Virol 73: 4465-4469.

Goldmann C, Stolte N, et al (2000). Packaging of small molecules into VP1-virus-like particles of the human polyomavirus JC virus. J Virol Methods 90: 85-90.

Greenlee JE (1989). In: Progressive multifocal leukoencephalopathy, Remington LS, Schwartz MN (eds.). p. 140, Blackwell Scientific, Boston.

Greenlee JE, Keeney PM (1986). Immunoenzymatic labelling of JC papovavirus T antigen in brains of patients with progressive multifocal leukoencephalopathy. Acta Neuropathol (Berl) 71: 150-153.
Hall CD, Dafni U, et al (1998). Failure of cytarabine in progressive multifocal leukoencephalopathy associated with human immunodeficiency virus infection. AIDS Clinical Trials Group 243 Team. NEngl J Med 338: 13451351.

Hamilton RS, Gravell M, et al (2000). Comparison of antibody titers determined by hemagglutination inhibition and enzyme immunoassay for JC virus and BK virus. J Clin Microbiol 38: 105-109.

Henson J, Saffer J, et al (1992). The transcription factor Sp1 binds to the JC virus promoter and is selectively expressed in glial cells in human brain. Ann Neurol 32: 72-77.

Hou J, Major EO (1998). The efficacy of nucleoside analogs against JC virus multiplication in a persistently infected human fetal brain cell line. J NeuroVirol 4: 451456.

Houff SA, Major EO, et al (1988). Involvement of JC virus-infected mononuclear cells from the bone marrow and spleen in the pathogenesis of progressive multifocal leukoencephalopathy. N Engl J Med 318: 301305.

Houston S, Roberts N, et al (2001). Failure of cidofovir therapy in progressive multifocal leukoencephalopathy unrelated to human immunodeficiency virus. Clin Infect Dis 32: 150-152.

Huang SS, Skolasky RL, et al (1998). Survival prolongation in HIV-associated progressive multifocal leukoencephalopathy treated with alpha-interferon: an observational study. J NeuroVirol 4: 324-332.

Jensen PN, Major EO (2001). A classification scheme for human polyomavirus JCV variants based on the nucleotide sequence of the noncoding regulatory region. J NeuroVirol 7: 280-287.

Kepes JJ, Chou SM, et al (1975). Progressive multifocal leukoencephalopathy with 10-year survival in a patient with nontropical sprue. Report of a case with unusual light and electron microscopic features. Neurology 25: 1006-1012.

Kerr D, Chang CF, et al (1994). Transcription of a human neurotropic virus promoter in glial cells: effect of YB-1 on expression of the JC virus late gene. J Virol 68: 76377643.

Khalili K, Krynska B, et al (1999). Medulloblastomas and the human neurotropic polyomavirus JC virus. Lancet 353: 1152-1153.

Komagome R, Sawa H, et al (2002). Oligosaccharides as receptors for JC Virus. J Virol 76: 12992-13000.

Koralnik IJ, Du Pasquier RA, et al (2002). Association of prolonged survival in HLA-A2+ progressive multifocal leukoencephalopathy patients with a CTL response specific for a commonly recognized JC virus epitope. JImmunol 168: 499-504.

Koralnik IJ, Du Pasquier RA, et al (2001). JC virus-specific cytotoxic T lymphocytes in individuals with progressive multifocal leukoencephalopathy. J Virol 75: 34833487.

Kunitake T, Kitamura T, et al (1995). Parent-to-child transmission is relatively common in the spread of the human polyomavirus JC virus. J Clin Microbiol 33: 14481451.

Levy RM, Ward S, et al (1997). Alternative delivery systems for antiviral nucleosides and antisense oligonucleotides to the brain. J NeuroVirol 3(Suppl 1): S74S75. 
Liu CK, Wei G, et al (1998). Infection of glial cells by the human polyomavirus JC is mediated by an N-linked glycoprotein containing terminal alpha(2-6)-linked sialic acids. J Virol 72: 4643-4649.

London WT, Houff SA, et al (1978). Brain tumors in owl monkeys inoculated with a human polyomavirus (JC virus). Science 201: 1246-1249.

Ma DD, Doan TL (1994). Antisense oligonucleotide therapies: are they the "magic bullets"? Ann Intern Med 120: 161-163.

Major EO (2001). Human Polyomavirus. In: Fields Virology, fourth edition, Knipe DM, Howley PM et al (eds.). pp. 2175-2196, Lippincott, Williams and Wilkins, New York.

Major EO, Amemiya K, et al (1990). Glial cells of the human developing brain and $\mathrm{B}$ cells of the immune system share a common DNA binding factor for recognition of the regulatory sequences of the human polyomavirus, JCV. J Neurosci Res 27: 461-471.

Major EO, Amemiya K, et al (1992). Pathogenesis and molecular biology of progressive multifocal leukoencephalopathy, the JC virus-induced demyelinating disease of the human brain. Clin Microbiol Rev 5: 49-73.

Mamidi A, DeSimone JA, et al (2002). Central nervous system infections in individuals with HIV-1 infection. $J$ NeuroVirol 8: 158-167.

Marra CM, Rajicic N, et al (2002). A pilot study of cidofovir for progressive multifocal leukoencephalopathy in AIDS. AIDS 16: 1791-1797.

McGuire D, Barhite S, et al (1995). JC virus DNA in cerebrospinal fluid of human immunodeficiency virusinfected patients: predictive value for progressive multifocal leukoencephalopathy. Ann Neurol 37: 395-399.

Miralles P, Berenguer J, et al (1998). Treatment of AIDSassociated progressive multifocal leukoencephalopathy with highly active antiretroviral therapy. AIDS 12: 24672472.

Miralles P, Berenguer J, et al (2001). Inflammatory reactions in progressive multifocal leukoencephalopathy after highly active antiretroviral therapy. AIDS 15: 19001902.

Monaco MC, Jensen PN, et al (1998). Detection of JC virus DNA in human tonsil tissue: evidence for site of initial viral infection. J Virol 72: 9918-9923.

Monaco MC, Sabath BF, et al (2001). JC virus multiplication in human hematopoietic progenitor cells requires the NF-1 class D transcription factor. J Virol 75: 9687-9695.

Okada Y, Endo S, et al (2001). Distribution and function of JCV agnoprotein. J NeuroVirol 7: 302-306.

Okada Y, Sawa H, et al (2002). Expression of JC virus agnoprotein in progressive multifocal leukoencephalopathy brain. Acta Neuropathol (Berl) 104: 130-136.

Padgett BL, Walker DL, et al (1971). Cultivation of papovalike virus from human brain with progressive multifocal leucoencephalopathy. Lancet 1: 1257-1260.

Pfister LA, Letvin NL, et al (2001). JC virus regulatory region tandem repeats in plasma and central nervous system isolates correlate with poor clinical outcome in patients with progressive multifocal leukoencephalopathy. $J \mathrm{Vi}$ rol 75: 5672-5676.

Pho MT, Ashok A, et al (2000). JC virus enters human glial cells by clathrin-dependent receptor-mediated endocytosis. J Virol 74: 2288-2292.

Portilla J, Boix V, et al (2000). Progressive multifocal leukoencephalopathy treated with cidofovir in HIV- infected patients receiving highly active anti-retroviral therapy. J Infect 41: 182-184.

Power C, Gladden JG, et al (2000). AIDS- and non-AIDSrelated PML association with distinct p53 polymorphism. Neurology 54: 743-746.

Raj GV, Khalili K (1994). Identification and characterization of a novel GGA/C-binding protein, GBP-i, that is rapidly inducible by cytokines. Mol Cell Biol 14: 7770-7781.

Raj GV, Khalili K (1995). Transcriptional regulation: lessons from the human neurotropic polyomavirus, JCV. Virology 213: 283-291.

Ranganathan PN, Khalili K (1993). The transcriptional enhancer element, kappa B, regulates promoter activity of the human neurotropic virus, JCV, in cells derived from the CNS. Nucleic Acids Res 21: 1959-1964.

Razonable RR, Aksamit AJ, et al (2001). Cidofovir treatment of progressive multifocal leukoencephalopathy in a patient receiving highly active antiretroviral therapy. Mayo Clin Proc 76: 1171-1175.

Ricciardiello L, Laghi L, et al (2000). JC virus DNA sequences are frequently present in the human upper and lower gastrointestinal tract. Gastroenterology 119: 1228-1235.

Richardson EP Jr (1961). Progressive multifocal leukoencephalopathy. N Eng J Med 265: 815-823.

Richardson EP, Webester HD (1983). Progressive multifocal leukoencephalopathy: Its pathologic features. In: Polyomaviruses and human neurological diseases, Sever JL, Madden DL (eds.). p. 191, Alan R Liss, New York.

Richardson-Burns SM, et al (2002). Progressive multifocal leukoencephalopathy and apoptosis of infected oligodendrocytes in the central nervous system of patients with and without AIDS. Arch Neurol 59: 19301936.

Safak M, Barrucco R, et al (2001). Interaction of JC virus agno protein with $\mathrm{T}$ antigen modulates transcription and replication of the viral genome in glial cells. J Virol 75: 1476-1486.

Schneider EM, Dorries K (1993). High frequency of polyomavirus infection in lymphoid cell preparations after allogeneic bone marrow transplantation. Transplant Proc 25: 1271-1273.

Staib C, Pesch J, et al (1996). p53 inhibits JC virus DNA replication in vivo and interacts with JC virus large T-antigen. Virology 219: 237-246.

Sumner C, Shinohara T, et al (1996). Expression of multiple classes of the nuclear factor-1 family in the developing human brain: differential expression of two classes of NF-1 genes. J NeuroVirol 2: 87-100.

Suzuki M, Zheng HY, et al (2002). Asian genotypes of JC Virus in Japanese-Americans suggest familial transmission. J Virol 76: 10074-10078.

Tantisiriwat W, Tebas P, et al (1999). Progressive multifocal leukoencephalopathy in patients with AIDS receiving highly active antiretroviral therapy. Clin Infect Dis 28: 1152-1154.

Taoufik Y, Delfraissy JF, et al (2000). Highly active antiretroviral therapy does not improve survival of patients with high JC virus load in the cerebrospinal fluid at progressive multifocal leukoencephalopathy diagnosis. AIDS 14: 758-759.

Tornatore C, Berger JR, et al (1992). Detection of JC virus DNA in peripheral lymphocytes from patients with and without progressive multifocal leukoencephalopathy. Ann Neurol 31: 454-462. 
Trowbridge PW, Frisque RJ (1995). Identification of three new JC virus proteins generated by alternative splicing of the early viral mRNA. J NeuroVirol 1: 195-206.

Walker DL, Padgett BL, et al (1973). Human papovavirus (JC): induction of brain tumors in hamsters. Science 181: 674-676.

Weber T, Major EO (1997a). Progressive multifocal leukoencephalopathy: molecular biology, pathogenesis and clinical impact. Intervirology 40: 98-111.

Weber T, Trebst C, et al (1997b). Analysis of the systemic and intrathecal humoral immune response in progressive multifocal leukoencephalopathy. J Infect Dis 176: 250-254.

Weber T, Turner RW, et al (1994). Progressive multifocal leukoencephalopathy diagnosed by amplification of JC virus-specific DNA from cerebrospinal fluid. AIDS 8: 49-57.

Wegner M, Drolet DW, et al (1993). Regulation of JC virus by the POU-domain transcription factor Tst-1: implications for progressive multifocal leukoen- cephalopathy. Proc Natl Acad Sci USA 90: 47434747.

Willoughby E, Price RW, et al (1980). Progressive multifocal leukoencephalopathy (PML): in vitro cell-mediated immune responses to mitogens and JC virus. Neurology 30: $256-262$.

Yang B, Prayson RA (2000). Expression of Bax, Bcl-2, and $\mathrm{P} 53$ in progressive multifocal leukoencephalopathy. Mod Pathol 13: 1115-1120.

Zambrano A, Kalantari M, et al (2002). Detection of human polyomaviruses and papillomaviruses in prostatic tissue reveals the prostate as a habitat for multiple viral infections. Prostate 53: 263-276.

ZuRhein GM (1969). Association of papova-virions with a human demyelinating disease, progressive multifocal leukoencephalopathy. Prog Med Virol 11:185247.

ZuRhein GM, Chou SM (1965). Particles resembling papovavirus in human cerebral demyelinating disease. Science 148: 1477-1479. 